\title{
Analyses of contact forces and kinetic motion on heavy load ball-screw
}

\author{
Chin-Chung Wei ${ }^{1, *}$ and Wen-Hsien $\mathrm{Kao}^{2}$ \\ ${ }^{1}$ Department of Power Mechanical Engineering, National Formosa University, No.64 Wenhui Rd. \\ Huiwei Township, Yunlin County, 63205, Taiwan R.O.C. \\ ${ }^{2}$ Institute of Mechatronoptic Systems, Chienkuo Technology University, Changhua, No. 1, Chieh \\ Shou N Rd., Chang Hua 500, Taiwan R.O.C.
}

\begin{abstract}
Effects of contact angle and groove factor of a heavy load ballscrew are discussed with the variation of contact forces at eight ball circulations. Contact forces are varying as a sinusoidal function of each circulation owing to the variation of phase angle. With the increase of contact angles, contact forces at each ball circulation are decreased and variation in each ball circulation. The decrease of the contact forces means that the contact stresses of contact areas are reduced. Fatigue life of raceways can thus be extended. Low groove factor can reduce skidding speed and friction coefficient. By the analyzing results, optimal transmission performance can be achieved in a heavy-loaded ball-screw.
\end{abstract}

\section{Introduction}

Heavy load ball-screw is wieldy used in plastic injecting mold machine, applying in injecting and load-lock axes. Non-preload is applied in a heavy load ball-screw. Operating conditions are low rotational speed and extremely high axial load, contact pressure on a contact area of ball-raceway can reach $1.8 \mathrm{GPa}$. Therefore, contact forces on each circulation of balls will not be equal owing to the contact mechanism. This will lead to serious wear occurred at the ball circulation which is nearby the flange of nut. The aim of the study is established a kinematic simulation model of multi-cycles ball-screw without preload in order to estimate contact forces on each circulation. This can help in the heavy loaded ball-screw design on uniform contact forces. Finite element model is made by a commercial software, Mash-Part, as shown in the Fig.1. Effective balls are 128 and set in the raceways, contact behavior is set as Hertz contact situation. An axial load is applied to a side of the flange of the nut.

The kinetic study of a ball-screw is started by Lin et al.[1]. They established fundamental coordinates to describe the motion of a ball's center, which is revoluted around a screw. Contact and kinetic behaviors among ball, and raceways of nut and screw are thus be obtained for discussion of geometrical parameters. Wei and Lin[2] considered effects of the

*Corresponding author: ccwei@nfu.edu.tw 
centrifugal force of the ball and lubrication at contact areas. Kinetic motion and contact behavior were introduced by a preloaded two-circulation ball-screw numerical model[3]. Sliding velocity and contact force will bring the wear occurred at the contact area between ball and raceway. A two body wear model considering the roughness effect was introduced in the ball-screw contact mechanism [4], the density of roughness peak and sliding speed are major factors to the wear of a preloaded ball-screw using in the normal operating conditions. Sliding roll ratio and position of pure rolling point are major factors to the kinetic motion and wear $[5,6]$. Contact mechanism and kinetic motion of a heavy load ballscrew are different to a normal situation. Non-preload is applied, and extreme high contact force has existed on the contact area. The study is present a theoretical model on the analyses of contact forces and kinetic motion of a heavy load ball-screw. A commercial software Mesh-Part is also used in the calculating of contact forces and kinetic behavior related to the contact angle and groove factor are discussed in the presented study.

\section{Analysing methodology}

The center position of any ball $o^{\prime}$ in a ball-screw can be determined by an absolute coordinate $(\mathrm{x}, \mathrm{y}, \mathrm{z})$, rotational coordinate $\left(\mathrm{x}^{\prime}, \mathrm{y}^{\prime}, \mathrm{z}^{\prime}\right)$, and moving coordinate $(\mathrm{t}, \mathrm{n}, \mathrm{b})$ as shown in the Fig.1. Contact coordinates (Xo, Yo, Zo) and (Xi, Yi, Zi) located on the contact ellipses at ball-nut and ball-screw contact areas, respectively. $\alpha_{0}$ and $\alpha_{i}$ are contact angles of ball-nut and ball-screw, respectively.

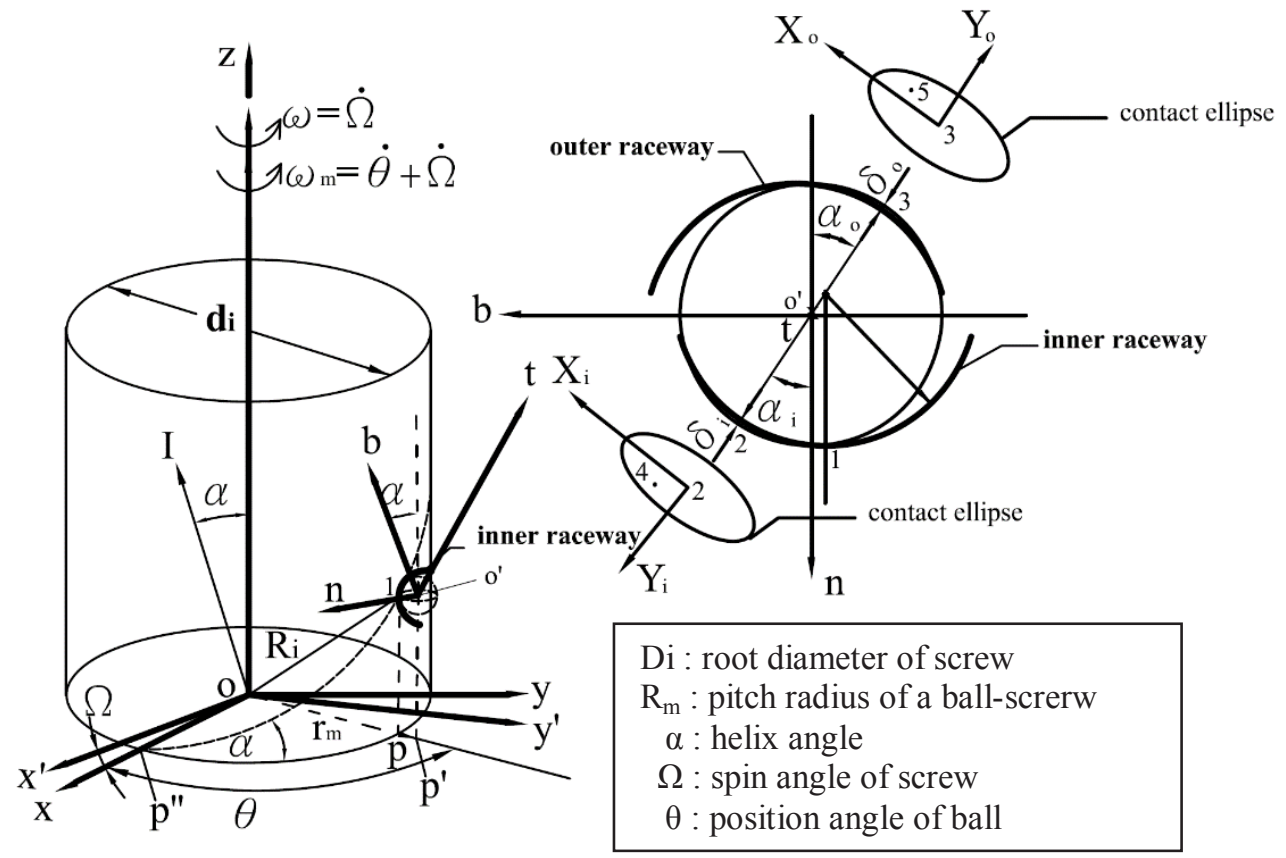

Fig. 1. Absolute, rotational and moving coordinates for a screw and any ball.

A finite element model has been established by a commercial software Mash Part, as shown in the Fig.2. Eight circulations are shown in the Fig. as L1, L2, L3, L4, R1, R2, R3, and R4. The axial load is applied to the top side of the nut, so the force is translated from the up nut to the down nut. Numerical parameters of a heavy load ball-screw are listed in the Tab.1. 


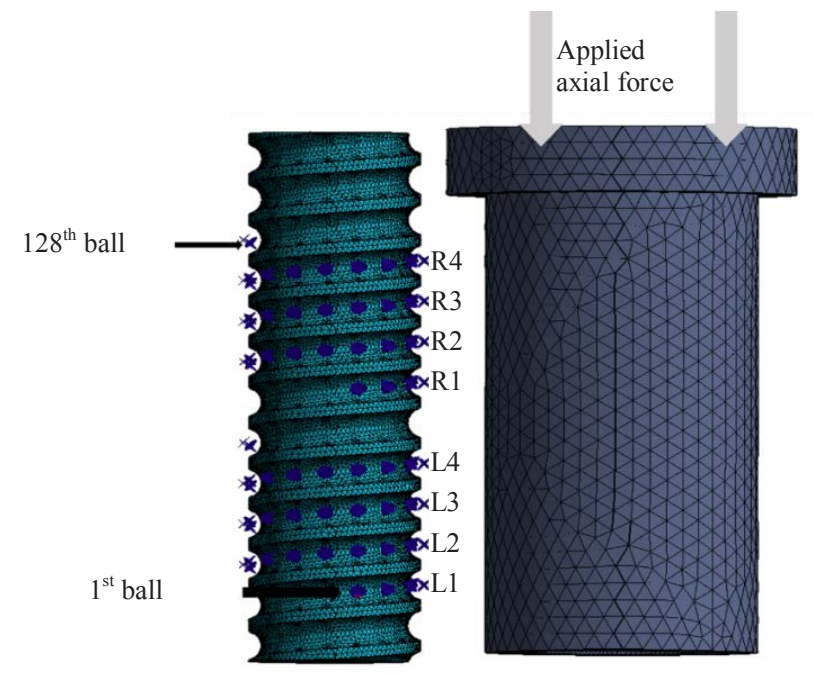

Fig. 2. FEM model for a double nut ball-screw.

Table 1. Parameters of a double-nut 8 circulations heavy load ball-screw.

\begin{tabular}{|c|c|}
\hline Parameters & Value \\
\hline Lead, $\mathrm{L}$ & $25 \mathrm{~mm}$ \\
\hline Dia. of a ball, $\mathrm{D}_{\mathrm{b}}$ & $19.05 \mathrm{~mm}$ \\
\hline Dia. of pitch, $\mathrm{D}_{\mathrm{m}}$ & $106 \mathrm{~mm}$ \\
\hline $\begin{array}{c}\text { Curvature of the } \\
\text { raceway, } \mathrm{r}_{\mathrm{o}, \mathrm{i}}\end{array}$ & $10.3 \mathrm{~mm}$ \\
\hline $\begin{array}{c}\text { Effective ball number } \\
\text { Axial load }\end{array}$ & $236 \mathrm{kN}$ \\
\hline $\begin{array}{c}\text { Rotational speed of } \\
\text { screw }\end{array}$ & $554 \mathrm{rpm}$ \\
\hline
\end{tabular}


Fig. 3. Geometry of contact area. 
Contact geometry is shown in the Fig.3. The contact area is varying with the variation of operating conditions. While setting the boundary on the FEM model, the contact area is assumed as a contact stripe [4]. In the Fig.3, the center of the raceway is No, and the contact distribution of angle is defined as $\theta_{o, i}$, which is written as

$$
\theta_{o, i}=\cos ^{-1}\left\{\frac{\left(r_{b} \times \cos \alpha_{o, i}\right)+\left[r_{o, i}-\left(R_{r}-R_{p}\right)\right]}{r_{o, r}}\right\} \pm \frac{\pi}{2}
$$

where, the subscript $\mathrm{o}$ and $\mathrm{i}$ denote the ball-nut and ball-screw contact sides. $r_{b}$ is the radius of a ball. $r_{o, i}$ is the radius of the raceway of the nut and screw, respectively. $\mathrm{R}_{\mathrm{r}}$ and $\mathrm{R}_{\mathrm{p}}$ are radii of screw's root and pitch, respectively. $\alpha_{o, i}$ is the contact angles of the raceway of the nut and screw, respectively.

By the past study of Wei[2], the orbital and spinning speeds of a ball along the screw, $\omega_{m}$ and $\omega_{R}$ are written as:

$$
\begin{aligned}
& \omega_{m}=\frac{\omega}{1-\frac{\left(1+\gamma^{\prime} C_{\alpha_{o}}\right)\left(c_{\alpha_{i}}+S_{\alpha_{i}}\right)}{\left(1-\gamma^{\prime} c_{\alpha_{i}}\right)\left(c_{\alpha_{o}}+S_{\alpha_{o}}\right)}} \\
& \omega_{R}=\frac{-\omega_{m}\left(1+\gamma^{\prime} C_{\alpha_{o}}\right) \sqrt{2} c_{\alpha}}{\gamma^{\prime}\left(c_{\alpha_{o}}+S_{\alpha_{o}}\right)}
\end{aligned}
$$

where, $\gamma^{\prime}=\frac{r_{b}}{r_{m}}, \omega$ is the rotational speed of the screw.

The value of the sliding speed between ball and raceway can be separated as tangential direction (t-axis direction) and vertical direction (X-direction), respectively. The t-direction is parallel to the moving direction of ball center. The X-direction is orthogonal to the $\mathrm{t}$ direction. These two sliding speeds can be written as :

$$
\begin{aligned}
& \mathrm{V}_{S t}=r_{b}\left(\omega_{t}-\omega S_{\alpha}\right) \\
& \mathrm{V}_{S X}=d\left(\omega_{m}-\omega\right)-r_{b}\left[\left(\omega_{b}-\omega C_{\alpha}\right) C_{\alpha_{i}}-\omega_{n} S_{\alpha_{i}}\right]
\end{aligned}
$$

The partial speed of $\omega_{R}$ at $\mathrm{t}, \mathrm{n}$ and $\mathrm{b}$ directions are written as

$\omega_{t}=\omega_{R} C_{\beta} S_{\beta^{\prime}} ; \omega_{n}=-\omega_{R} S_{\beta}$ and $\omega_{b}=-\omega_{R} C_{\beta} C_{\beta^{\prime}}$, the angle $\beta$ and $\beta^{\wedge}$ are spinning angles at orthogonal directions, respectively. The sliding speed at the $\mathrm{X}$-direction is due to the spinning and yawing motion of a ball. It means the skidding motion between ball and raceway.

\section{Results and discussions}

A heavy load ball-screw is applied an extremely high axial load on the nut. Each circulation balls are carried high contact force, and contact forces are greatly increased with the increase of ball numbers, as shown in Fig.4. The black line separates right and left nuts, contact forces at the left nut are much lower than the right nut. Contact forces are varying as a sinusoidal curve due to the effect of the phase angle of each ball is different. The increase of contact angles can decrease the contact forces. 


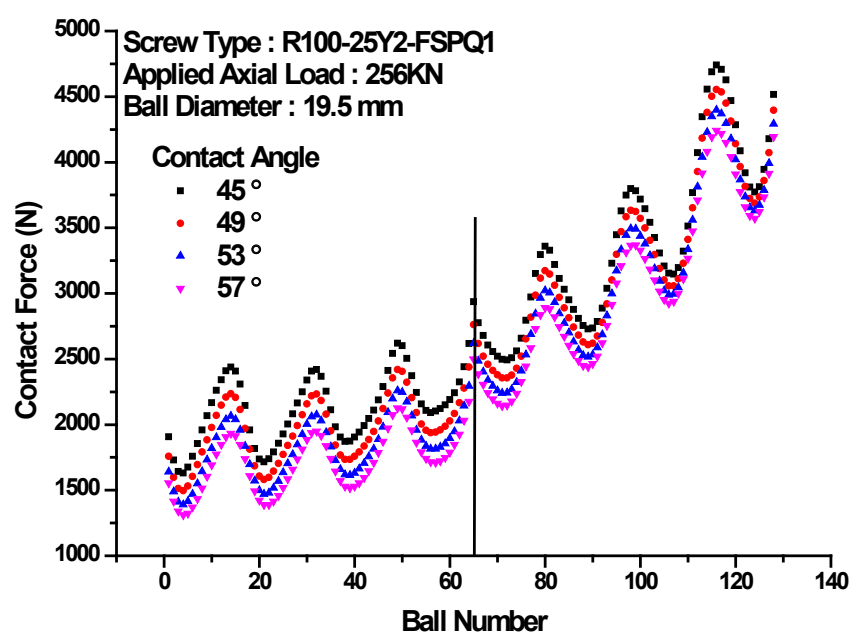

Fig. 4. Contact forces distribution V.S. contact angles.

Contact forces are averaged at each circulation and shown in the Fig. 5. The difference of contact forces at each contact angle condition is similar, but the latest circulation is not the same. This is due to the applied axial load is acted on the right end of the nut, the latest circulation is the first part to bear the force and then decay with the circulations. Therefore, the right nut bears much higher contact forces than the left nut. The 7 th and 8 th circulations, R3 and R4, thus bear similar contact forces. In the figure, the increase of contact angle can effectively reduce the contact force at each circulation. Because higher contact angle can let the radial part contact force become smaller. But too large contact angle will greatly increase the contact stress of top raceway, it will lead to fatigue failure happened on it.

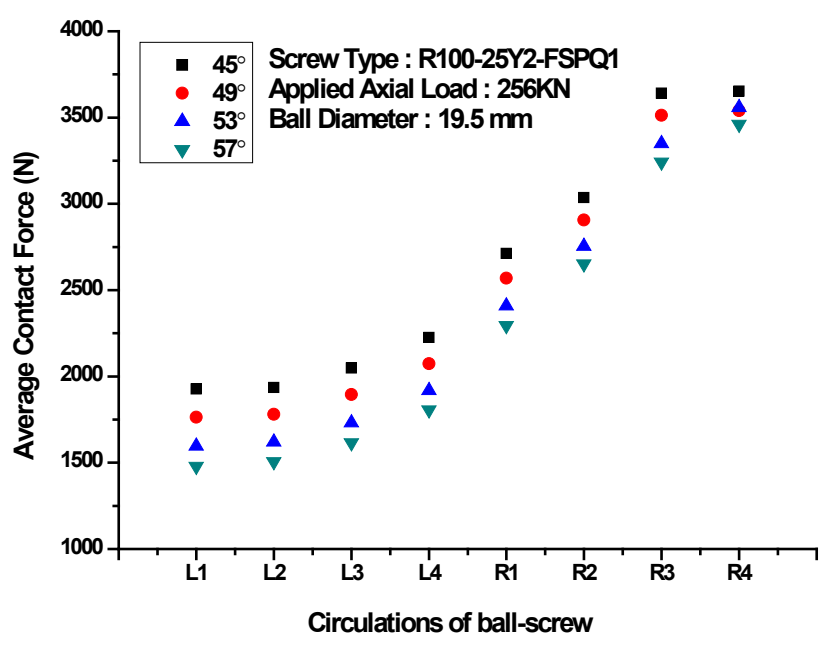

Fig. 5. Average contact forces vary with contact angles and circulations.

The design of groove factor is very important to the contact mechanism of a heavy load ball-screw. The groove factor is well known as the ratio of the radius of the raceway to the diameter of a ball. When the groove factor is near to 0.5 , the contact area between ball and 
raceway has the largest value. The contact angle is also varied with the variation of the groove factor, as shown in the Fig.6. The decrease of the groove factor increases the contact angle and reduces the contact forces, especially at contact areas of the left nut.

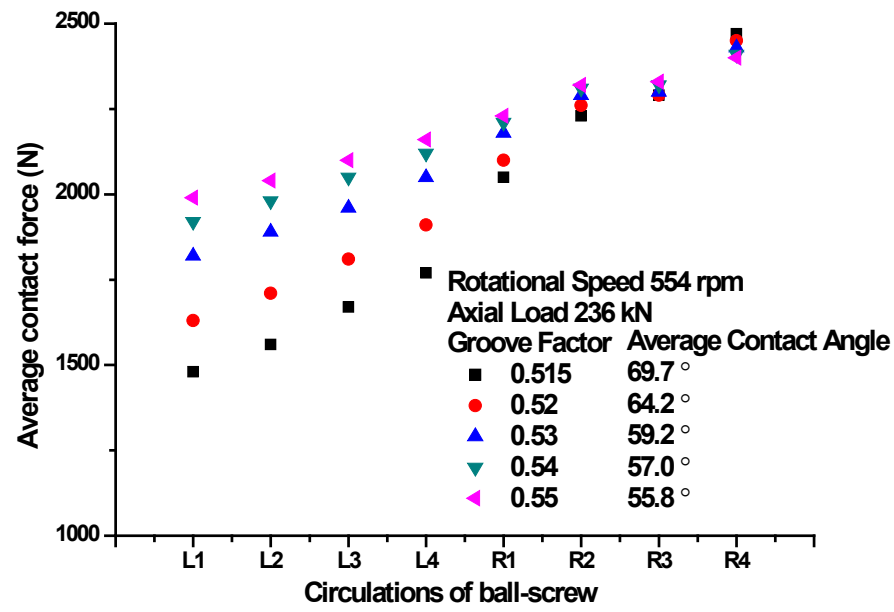

Fig.6. Average contact forces varying with the groove factor and circulations.

Friction coefficient increases with the increase of the groove factors due to the sliding speed are also increased. It's interesting in the increases of sliding speeds along t- and X-direction is different. The value of sliding speed at $\mathrm{t}$-direction is greater than $\mathrm{X}$-direction, but the rising slope is not so large. The rising of sliding speed at X-direction with the increase of the groove factor means the skidding motion on contact area becomes serious. So the friction coefficient is also rising with the increase of the groove factor.



Fig.7. Frition coefficient varies with the groove factor and sliding speeds.

\section{Conclusions}

The study uses a commercial software Mash-Part and creates a theoretical method for analyzing contact and kinetic behavior to a heavy load ball-screw under different raceway geometry conditions. The contact angle and groove factor were discussed for the lowest 
contact forces to multi-circulations. Increasing the contact angle or reducing the groove factor can effectively decrease contact forces of each circulation. The friction coefficient is dominated by the sliding speed at X-direction, which is along the raceway and vertical to the moving direction of ball centre. The speed means the skidding motion between ball and raceway. Lower groove factor has lower sliding speed and friction coefficient. The aim of the study indicates how to reduce contact force and friction and can help to design high transmission efficiency and fatigue life heavy-load ball-screw.

\section{Acknowledgment}

The author gratefully acknowledges the Ministry of science and technology (MOST) and Hiwin Technology Co. in Taiwan, R.O.C., whose supported this research under grant Most106-2262-E-150-001-CC2.

\section{References}

1. M.C. Lin, B. Ravani, S. A. Velinsky, ASME J. Mech. Des, 116, 849 (1994)

2. C.C. Wei, J.F. Lin, J. Mech. Des, 125(4), 717 (2004)

3. C.C. Wei, J.F. Lin, and J. H. Horng, Tri. Int., 42, 1816 (2009)

4. C.C. Wei, R.S. Lai, Mech. and Machine Theory, 46, 880 (2011)

5. C.C. Wei, W.L. Liou, and R. S. Lai, Wear, 292-293, 111 (2012)

6. J.Z. Hu, M. Wang, T. Zan, Mech. and Machine Theory, 79, 158(2014) 